\title{
ENTERO-CYSTOPLASTY IN CONTRACTED BLADDER COMPLICATED BY HYDRONEPHROSIS*
}

\author{
By M. G. Pelot, M.D. \\ L'Institution Nationale des Invalides, Paris
}

THE presence of dilatation of the upper urinary tract, connected with irreversible changes in the bladder, may be an indication for entero-cystoplasty in paraplegia.

The bladder lesion is, in most cases, contracture of the detrusor, which is fixed by fibrosis, or more rarely a distension with permanent atony, this latter complication being the most dangerous for renal function. In both cases, the situation can be complicated by a permanent reflux. The usual treatment of this hydronephrosis is the diversion of the urine by cutaneous ureterostomy. Six of our three hundred and fifty patients with spinal injuries benefited from this diversion. The first operated case has still good renal function, after eleven years of ureterostomy.

In utilising the entero-cystoplasty the urologist's twofold task is to save the kidney and restore the bladder function and at the same time avoid an additional disability to his patient. Since 1959, two entero-cystoplasties have been performed in the Centre of the National Institute for Invalids in Paris. In both cases, a segment of the sigmoid colon was used to increase the capacity of the bladder.

Hereunder, is a summary of these two cases:

Case I. In February 1959, the first colo-cystoplasty for bilateral uretero-hydronephrosis was performed in a paraplegic of four years' standing with a complete lesion due to fracture of $\mathrm{T}_{9}$ (fig. I). Fibrous contracture of the bladder was promoted by an early suprapubic cystostomy, which was kept open during the first year after the accident, resulting in severe urinary infection and complicated by renal calculosis on the right side, which was operated upon. From 1957 to 1958, the capacity of the bladder was reduced from $200 \mathrm{cc}$. to $60 \mathrm{cc}$. (fig. 2). There was no ureteric reflux and the blood urea was normal.

At operation, the bladder was the size of an orange with a very thick wall. A segment of $20 \mathrm{~cm}$. of sigmoid colon, closed at either end, was anastomosed laterally in two flaps to the bladder. After resection of the upper part of the bladder, extraperitonealisation of the colonic-vesical reservoir was carried out. An indwelling catheter was left in situ for a month. After this operation, the bladder capacity increased from 60 to $350 \mathrm{cc}$. (fig. 3), but micturition, promoted by tapping the hypogastric region, was poor, and the residual urine varied from I 50 to $200 \mathrm{cc}$. There was no sensation of fullness. On the other hand, the saving of the kidneys, which was the main aim of the operation, had been achieved, the pyelo-ureteric dilatation disappeared and the kidney function became normal (fig. 4).

Case 2. The second colo-cystoplasty was performed in October 1959, for a moderate pyelo-ureteric dilatation with permanent vesico-ureteric reflux on the left side (fig. 5). There was a small bladder, following suprapubic cystostomy of one year duration, and there had been numerous urinary flare-ups. The bladder and kidney complications appeared three years after a paraplegia of spastic type, caused by a fracture of $T_{7}$. The

* Read at the Scientific Meeting of the International Medical Society of Paraplegia. July 1962 . 


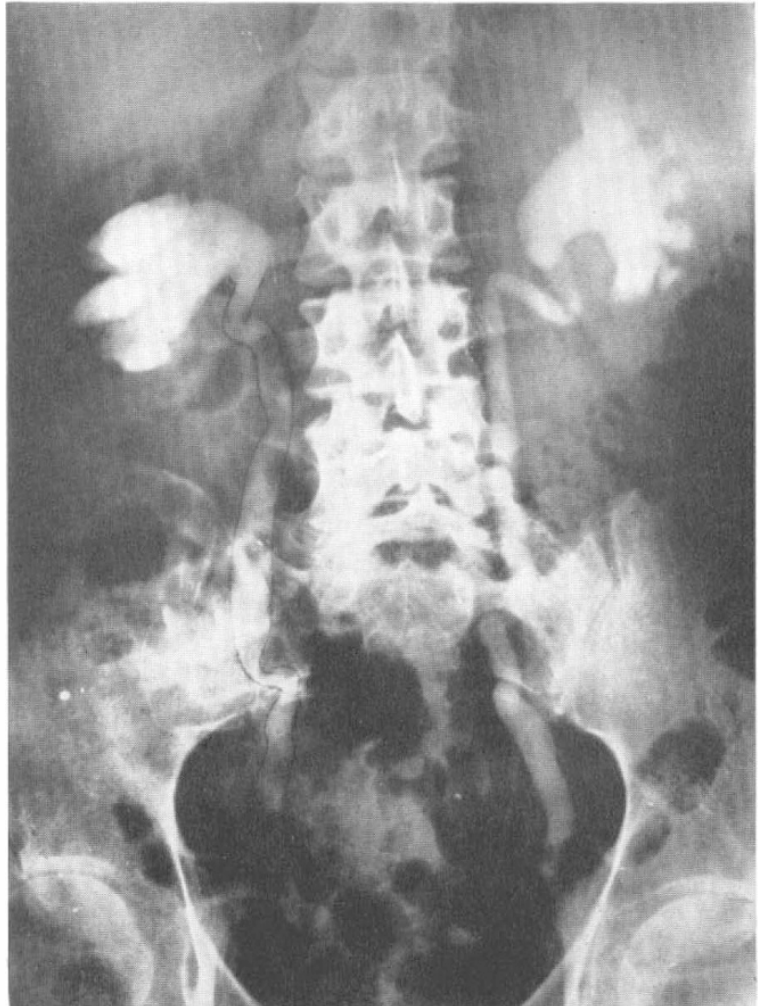

FIG. I Paraplegia complete T9. Before the colocystoplasty: bilateral hydronephrosis.

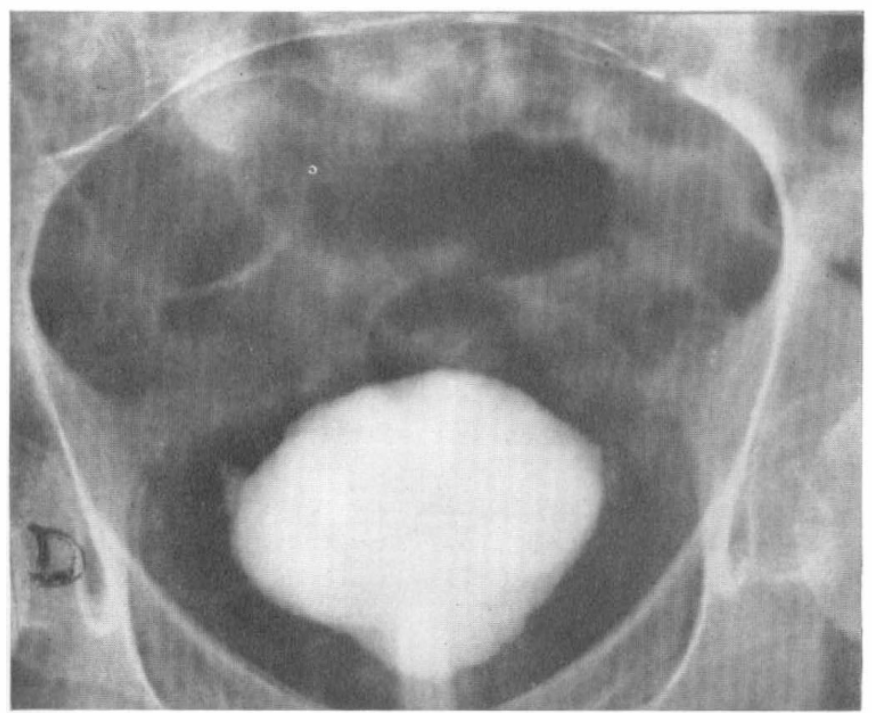

Fig. 2 Before the operation: small contracted bladder. 


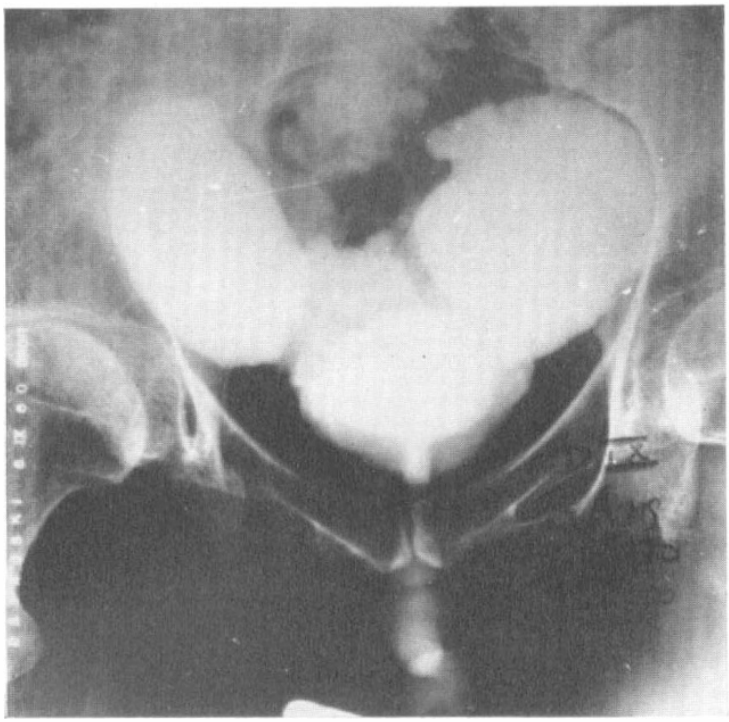

FIG. 3

Bladder after the colo-cystoplasty.

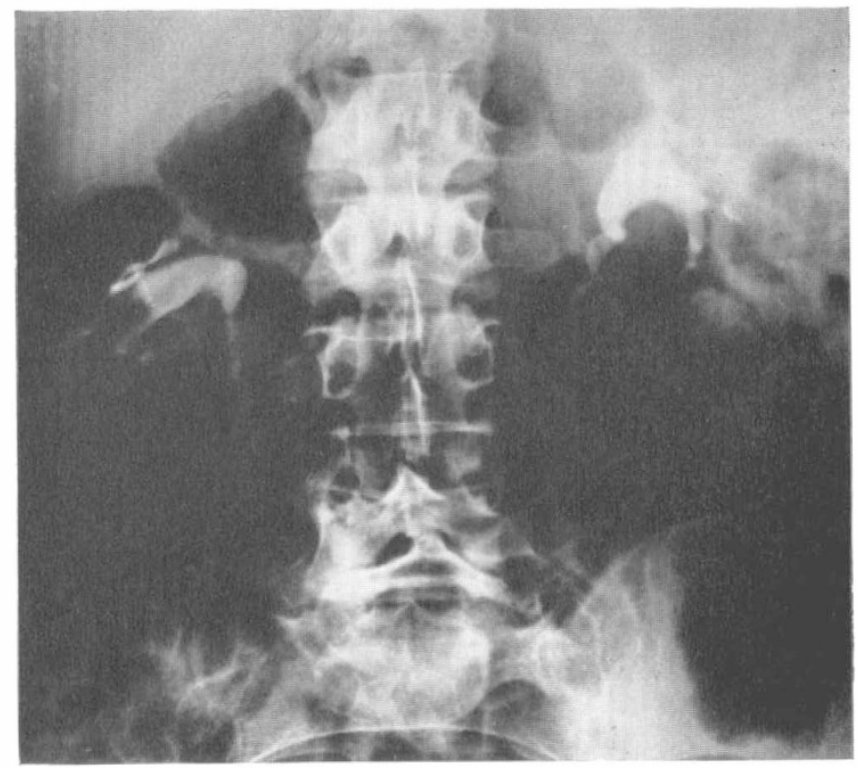

FIG. 4

Three years after the colo-cystoplasty: disappearance of pyelo-ureteric dilatation. 


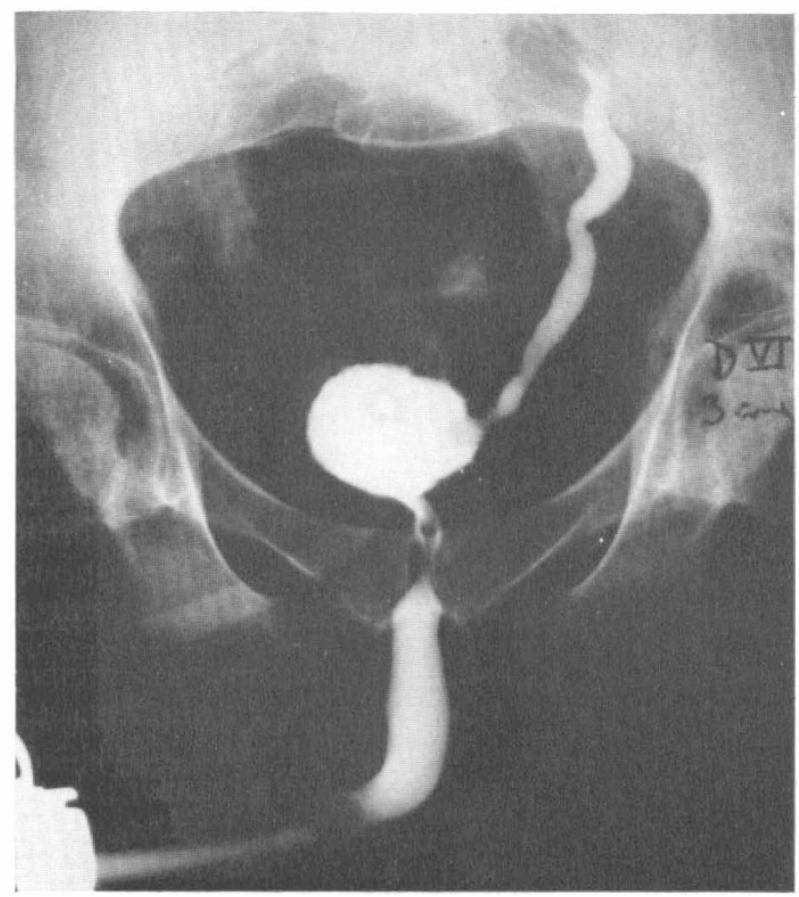

FIG. 5

Paraplegia complete $\mathrm{T}_{7}$. Before the operation: small bladder with a left ureteral reflux.

operation was identical to the procedure in Case I, with the exception that it was impossible to complete the final extraperitonealisation, owing to obesity of the patient.

One month after the operation, aggravation of the contractures of the legs necessitated an intrathecal alcohol block, which had been postponed until then in order not to interfere with erections. The alcohol block did not improve the contracture of the bladder. In this case, there has been good improvement of the bladder function, the capacity of the new bladder being 300 to $250 \mathrm{cc}$. Fullness is felt as a burning sensation in the hypogastric region and micturition is started by voluntary efforts, in spite of paralysis of the abdominal muscles. Residual urine is $50 \mathrm{cc}$.

On the other hand, there is the persistence of a reflux with pyelo-ureteric hypotonia (fig. 6). Flare-ups are rare, and an I.V.P. carried out three years after operation showed no renal dilatation (fig. 7). A resection of the bladder neck was performed to facilitate micturition. However, an indwelling catheter had to be inserted during the last few months because of a urethral fistula.

Comments. This brief experience seemed worth while reporting, although the results obtained are not perfect. Until now, entero-cystoplasty of the neurogenic bladder has remained an exceptional procedure. Since the two cases published by J. Cibert et al. in 1957, only five cases have been published in France: J. M. Vernet et al. (1960), M. P. Bitker (1960), G. Pelot and R. Voegtlin (I96I), and E. Truc et al. (1962).

Indication. The mediocre function of the intestinal bladders has not encouraged the general acceptance of this complicated operation. Nevertheless, 


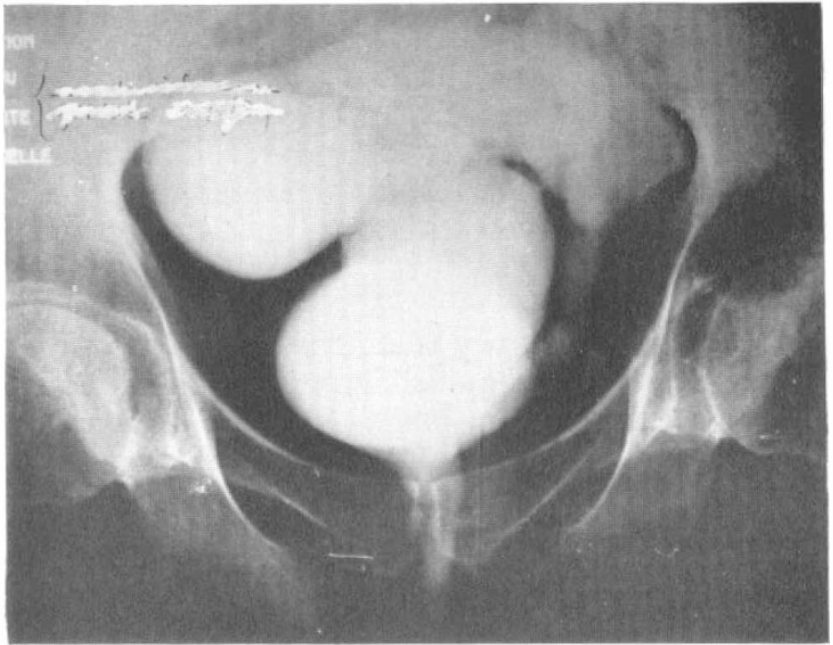

FIG. 6

Bladder after operation: persistence of the left-sided reflux.

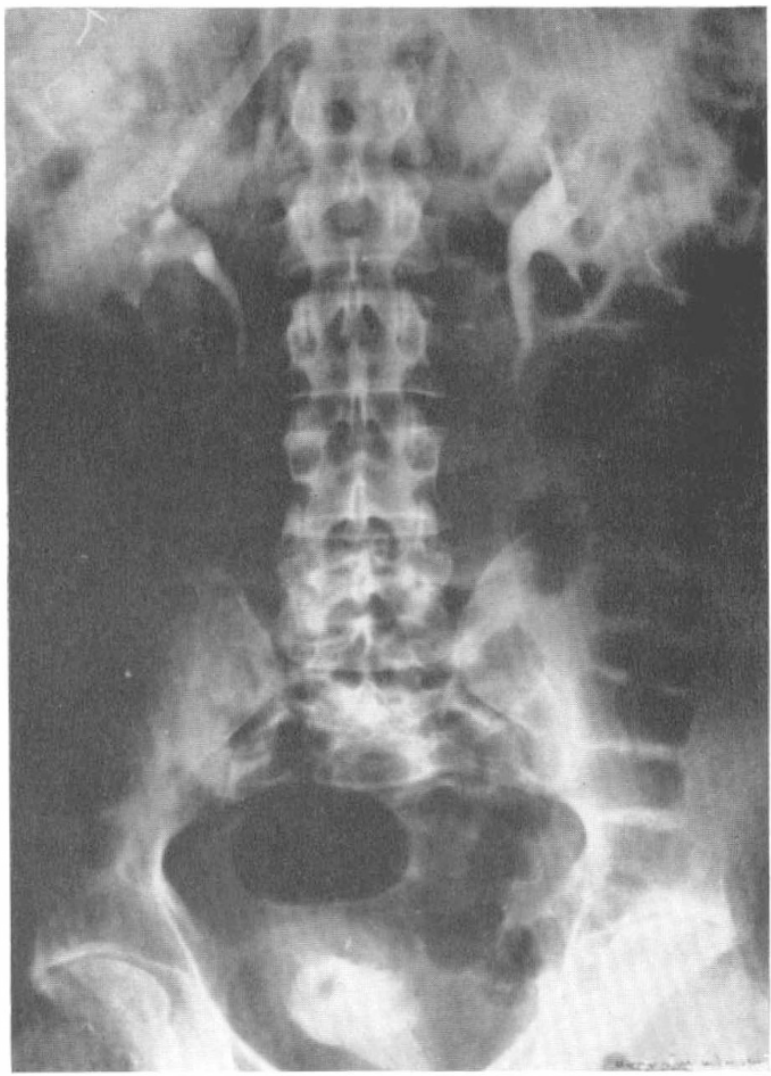

FIG. 7

Three years after the operation the I.V.P. is normal. 
when a neurogenic bladder has lost its function as a reservoir, thus endangering the kidney, an entero-cystoplasty is justified. One renal complication-hydronephrosis - for which a diversion of the urine may become necessary, can in certain cases be reduced after entero-cystoplasty. However, if a permanent vesico-renal reflux complicates the situation the result would appear to be more uncertain. In case of marked reflux, combined with renal deficiency, it would be advisable to use the cutaneous ureterostomy.

Technique. Certain points may be emphasised: Utilisation of a part of the sigmoid is more appropriate than the small intestine for the function of a reservoir. The graft should be at least $20 \mathrm{~cm}$. long. The use of non-absorbable suture material should be excluded for the entero-vesical anastomosis. The resection of the detrusor should be large enough to ensure a large vesico-intestinal communication.

The complete extraperitonealisation is of no use unless there is a good drainage of the urine for at least three weeks.

\section{SUMMARY}

The entero-cystoplasty, which is a major operation, is well tolerated by a traumatic paraplegic, provided the patient is in good condition and the operation is carried out in a specialised centre. Isolated cases are too recent to allow definite conclusions, but the results obtained encourage perseverance on these difficult lines in order to progress in the urological treatment of paraplegics.

\section{RÉSUMÉ}

L'entérocystoplastie, opération majeure, est bien supportée par un traumatisé médullaire en bonne condition et en milieu spécialisé. Des cas isolés et trop récents ne permettent pas de conclure définitivement mais des résultats encourageants engagent à persévérer dans une voie difficile suceptible de faire progresser le traitement urologique des paraplégiques.

\section{ZUSAMMENFASSUNG}

Die Entero-Cystoplastie, die eine schwierige Operation darstellt, kann von einem Querschnittsgelähmten gut vertragen werden, vorausgesetzt der Patient befindet sich in einem guten Allgemeinzustand und die Operation in einer Specialabteilung ausgeführt wird. Isolierte Fälle sind von zu kurzer Beobachtung, um definitive Schlüsse zu erlauben. Aber die bisherigen Resultate ermutigen, auf diesem schwierigen Gebiet weiter zu arbeiten in der Hoffnung auf eine Verbesserung der urologischen Behandlung von Querschnittsgelähmten.

\section{REFERENCES}

Bitker, M. P. (I960). T. de Chirurgie, Octobre, 80, 370.

Cibert, J., ReVol, M., \& RigondeT, G. (I958). F. d'Urologie, 4-5, 256, 257.

Pelot, G., \& Voegtlin, R. (I96I). $\mathcal{F}$. d'Urologie, 3, I80-I 88.

Truc, E., Levallois, M., Grasset, D., \& Badosa, J.'(I962). F. d'Urologie et de Néphrologie, 3, 207-2I4.

Vernet, J. M., Soler-Rosello, A., Verly, J. M., \& Gosalbez, R. (i960). F. d'Urologie, I, 2, 7 à 19. 


\section{Discussion} bladder.

Benassy, f. (France) reported two cases developing osteoporosis following ileal

Griffiths, I. H. (England) had had some experience with this type of operation but only in non-paraplegic patients. He asked Dr. Pelot whether he used the bowel as a flap or as a tube.

Pelot, $G$. (France) replied that he used it as a tube.

Griffiths, I. H. (England): He also had used the bowel as a tube but found the flap more satisfactory, as the flap did not develop into a diverticulum so much as the tube. $\mathrm{He}$ had carried out this operation in tuberculosis patients without paraplegia. He also referred to ureterostomy, which he had done at Stoke Mandeville, and he found this operation satisfactory. The only difficulty was keeping the ureteric orifices open and preventing stricture.

Pelot, G. (France) said that in a case of paraplegia the cystoplasty was better tolerated than the ileal bladder.

Walsh, $\mathcal{F} . \mathcal{F}$. (England) reported on the experience of the ileal bladder in paraplegic patients admitted to Stoke Mandeville. This operation was followed by certain late complications, such as bowel obstruction due to adhesions, and in two patients admitted to Stoke Mandeville with obstruction one required immediate operation. The ileal bladder did not prevent ascending infection resulting in renal failure. As was the experience of Pelot, at Stoke Mandeville the skin-ureterostomy was found to be quite satisfactory.

Pelot, G. (France) thought it of great importance that these operations be carried out in special centres, where indications for this operation could be ascertained more accurately.

Gibbon, N. (England): Their experience with entero-cystoplasty was limited, and he referred in particular to high residual urine. He asked Pelot whether he had had trouble with high residual urine after entero-cystoplasty and what steps had been taken to reduce this.

Pelot, G. (France): Resection of the bladder neck was one important part of the operative procedure, particularly in small sclerotic bladders, where the back pressure was particularly great.

Maury, M. (France) felt it important to test the elasticity of the bladder, before any operation were performed. This could be done by either epidural or intrathecal anaesthesia.

Guttmann, L. (England): One had to distinguish between two groups of bladders: (I) the bladder which was small but could easily be dilated following intrathecal alcohol injection to a satisfactory size, and he felt that this simple procedure should be tried before contemplating any plastic operation to the bladder and ureter; (2) the small fibrotic bladder in which alcohol block had produced no improvement. In such a case, entero-cystoplasty seemed to be a less dangerous procedure than the ileal bladder. 